\title{
Reconsidering the Notion of User Experience for Human-Centered Design
}

\author{
Hiroyuki Miki \\ Oki Electric Ind. Co., Ltd., R\&D Center \\ 1-16-8 Chuou, Warabi-shi, Saitama 335-8510, Japan \\ hmiki@cf.netyou.jp
}

\begin{abstract}
Recently, the word "User Experience (UX)" has been often used in usability-related areas such as web design and system design. Although it was defined in ISO 9241-210 and its importance has been growing, details of the notion and results of introduction of it have not been well clarified yet. After reviewing related research results, this paper firstly summarizes a historical transition from usability to UX by seeing transitions from ISO/IEC 9126-1 to ISO/IEC 25010 in the software quality international standard, and from ISO 13407 to ISO 9241-210 in the ergonomics international standard. Then details of the notion are discussed and a framework for UX is proposed.
\end{abstract}

Keywords: User Experience, Usability, ISO 9241, ISO 13407, ISO/IEC 25010, Guideline, American Customer Satisfaction Index, Customer Expectation Management, Theory of Consumption Value, Persona.

\section{Introduction}

Usability is a notion, for example, that addresses a degree of how easy one can use products, systems, or services. As products, systems, or services become complex and provide high-level functions to the user, designing and evaluation usability become more difficult. In addition, as business competitions go world wide and become fierce, conditions of successful products, systems, or services become more complex [3].

Norman considered this kind of changes and claimed that broader scope than usability should be considered [14]. He claimed that the user wants not only a good usability but also a high UX to be truly pleased with good products, systems, or services. To consider UX, one needs to consider user's good/ bad feelings and responses, namely results of relating products, systems, or services more than usability. It was the first time that UX was mentioned by an opinion leader of usability.

Since international standards provide common bases for international businesses, it was quite reasonable that the word UX was introduced in them under the changes described above. However, details of the notion and results of the introduction of it are not well clarified yet.

After reviewing related research results, this paper firstly reviews a historical transition from usability to UX by seeing transitions from ISO/IEC 9126-1 to ISO/IEC 
25010 in the software quality international standard, and from ISO 13407 to ISO 9241-210 in the ergonomics international standard. Then details of the notion are discussed and a framework for UX is proposed.

\section{Background}

Before the introduction and the discussion of UX in international standards, recent research results are briefly reviewed.

\subsection{Various Definitions of UX}

After the publishing of Norman's book in 1998, many definitions of UX have been proposed so far reflecting diversity of related areas and concepts. For example, 27 definitions are shown at "All About UX" web page (http://www.allaboutux.org/). The following are three definitions among them. Although contents of the definitions vary, they are quite broad in their meanings.

- UXPA

Every aspect of the user's interaction with a product, service, or company that make up the user's perceptions of the whole. User experience design as a discipline is concerned with all the elements that together make up that interface, including layout, visual design, text, brand, sound, and interaction. UE works to coordinate these elements to allow for the best possible interaction by users.

- Microsoft

An activity of encounter by a computer user with the auditory and visual presentation of a collection of computer programs. It is important to note that this includes only what the user perceives and not all that is presented.

- $\quad$ ISO 9241-210 [9]

A person's perceptions and responses that result from the use or anticipated use of a product, system or service.

\subsection{Time Span of UX: User Experience White Paper}

User experience white paper [16] is a result from discussions among the invited experts of the Demarcating User Experience seminar in 2010. It goes beyond definition discussions, describes core concepts of UX, and clarifies different perspectives of UX. It addresses what are UX and what are not UX, time span of UX, factors affecting UX, and UX as a practice. In the description of UX as a practice, it refers to human-centered design (HC) $[8,9]$ and briefly explained what have to be done in HCD. Although it is a twelve page document, it briefly summarizes arguments at the time well. Fig.1 from the document shows time spans of UX, the terms to describe the kind of UX related to the spans, and the internal process taking place in the different time spans. While usability is on "during usage" only, UX covers all spans. 


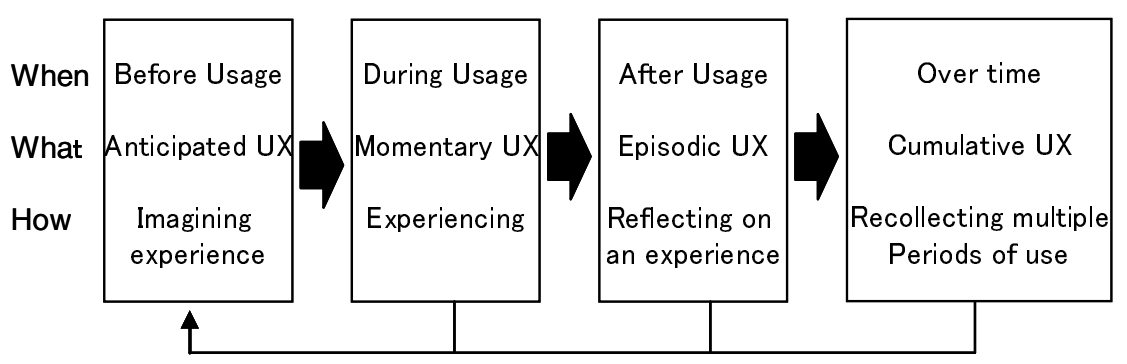

Fig. 1. Time spans of UX, the terms to describe the kind of UX, and the internal process taking place. (This is created based on Fig.2 of the paper [16].)

\subsection{Dimensions and Data Collection Methods for UX}

Bargas-Avila and Hornbæk summarize dimensions and data collection methods for UX [2]. While the dimensions are more than usability dimensions, the data collection methods are similar to usability ones.

Table 1. UX dimensions and data collection methods for UX (created from Table 2, 3 of [2])

\begin{tabular}{|l|l|}
\hline UX dimension & $\begin{array}{l}\text { Generic UX, Affect/Emotion, Enjoyment/Fun, Aesthetic/Appeal, } \\
\text { Hedonic Quality, Engagement/Flow, Motivation, Enchantment, } \\
\text { Frustration, Other Constructs }\end{array}$ \\
\hline $\begin{array}{l}\text { Data collec- } \\
\text { tion method }\end{array}$ & $\begin{array}{l}\text { Questionnaires, Interviews (semi-structured), User Observation } \\
\text { (live), Videorecordings, Focus Groups, Interviews (open), Di- } \\
\text { aries, Probes, Collage or Drawings, Photographs, Body move- } \\
\text { ments, Psychophysiological Measures, Other Methods }\end{array}$ \\
\hline
\end{tabular}

\subsection{CHI SIG and Workshop Related to UX}

Since 2008, a workshop on UX has been held at CHI conference every year. In the CHI'11 workshop, UX theories and theoretical frameworks were discussed. Based on the discussion, Obrist et al. [15] propose seven theory categories and nine disciplines. Severn theory categories are a) human/user, b) product/artifact, c) user/artifact/environment relations, d) social nature of UX, e) design focus, f) frameworks involving several themes from a) to e), and g) even broader frameworks related to human existence. Meanwhile, nine disciplines are psychology, sociology, marketing, philosophy, communication, education, art, anthropology, and design. Both the theory categories and the disciplines are quite broad.

\subsection{Related Theory (1): Theory of Consumption Value in Marketing}

Except for the case that UX simply represents an event, UX is subjective and is with some evaluation value like good or bad. About value, the theory of consumption value 
(TCV) [17] in marketing area decomposes it into five sub values to explain consumer choices: functional value, social value, emotional value, epistemic value, and condition value. Moser et al. [12] suggested using the five sub values and additional interpersonal value as sub notions of UX. For example, while the functional value corresponds to most notions of usability such as efficiency and effectiveness, other sub values reasonably cover other notions compared with UX dimensions in section 2.3. TCV is referred to create an UX framework in section 4.3.

\subsection{Related Theory (2): American Customer Satisfaction Index in Service Sciences}

Satisfaction is related to UX in the sense that both represent some subjective feelings resulting from some perception and/or action. In Service Science area, American Customer Satisfaction Index is a popular method to treat satisfaction. It is used to compare different services such as hotel service, airline service, retail service, and so on. Starting from Customer Expectation, the index model shows causal relations of indices which are important to evaluate services. While Customer Expectation evaluates the customer's anticipation of the quality of products of services before an actual service, Perceived Quality and Perceived Value evaluate the quality during a service followed by Customer Complaints and Customer Royalty for the quality after a service. It should be noted that Perceived Value is a measure of quality relative to price paid. ACSI is used to create an UX framework in section 4.3.

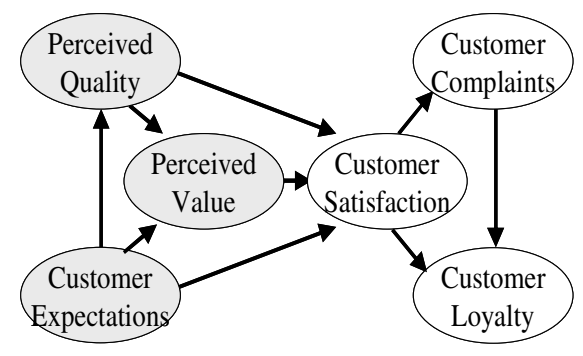

Fig. 2. American Customer Satisfaction Index (Arrows represent influence. This is created based on http://www.theacsi.org/index.php).

\subsection{Practical Guidelines Related to UX}

Apart from academic distinctions of conceptual categories, there are practical design guidelines to provide high UX. For example, Persona method and accompanied guidelines are very common in the usability community as a core method to provide high UX [4]. Other examples include iOS human interface guidelines [1] in which most descriptions are on usability except for those on mobile devices. 


\section{Usability and UX in International Standards}

In the previous section, a wide range of related research results of UX are reviewed. International Standards, on the other hand, have the specific role to provide business organizations with technical standards. Currently, UX related standards are built mainly by the ergonomics committee (ISO/TC159) and the software committee (JTC1/SC7). In this section, fundamental standards related to UX are reviewed: ISO 9241-11:1998 [11], ISO/IEC 9126-1:2000 [6], ISO 9241-210:2010 [9], and ISO/IEC 25010:2011 [7].

\subsection{ISO 9241-11:1998 and ISO/IEC 9126-1:2000}

ISO 9241 part 10 - part17 are series of international standards on Ergonomic requirements for office work with visual display terminals (VDTs). In ISO 9241-11 (Guidance on Usability), the terminology "usability" was for the first time defined in international standards as the following.

- Usability in ISO 9241-11:1998 [10]:

Extent to which a product can be used by specified users to achieve specified goals with effectiveness, efficiency and satisfaction in a specified context of use.

This definition which emphasizes effectiveness, efficiency and satisfaction was different from previous definitions which emphasized ease of operation. For example, before ISO 9241-11, Nielsen [13] defined usability as ease of operation in parallel with utility, and defined usefulness as composed of usability and utility. In short, the definition of ISO 9241-11 is almost same with Nielsen's definition of usefulness. In this sense, the definition of ISO 9241-11 is broader than previous definitions. This difference is often described as difference between "small usability" and "big usability": Namely, while Nielsen's definition is called as "small usability", the definition of ISO 9241-11 is called as "big usability". Since Norman called "small usability" as usability in a similar way with Nielsen, UX is conceptually closer to "big usability".

In software quality standards, on the other hand, ISO/IEC 9126-1 defines usability as "small usability" composed of understandability, learnability, operability, attractiveness, and usability compliance. It also defines "big usability" as "quality in use". Hence, ISO/IEC 9126-1 defines usability differently from ISO 9241-11. Although UX is conceptually close to usability of ISO 9241-11 and to "quality in use" of ISO/IEC 9126-1, differences among them were unclear.

\subsection{ISO 9241-210:2010 and ISO/IEC 25010:2011}

In 2010, ISO 13407 (Human-centred design processes for interactive systems) [8] was renewed and renumbered as ISO 9241-210 (Human-centred design for interactive 
systems) [9] in ergonomics standards. In ISO 9241-210, UX is for the first time defined in international standards as the following.

- User Experience in ISO 9241-210:2010 [9]:

person's perceptions and responses resulting from the use and/or anticipated use of a product, system or service.

However, there are three other definitions described as notes in the document, which showed difficulties in defining it. In addition, there is no description about differences between usability and UX.

ISO/IEC 9126 series have also been under renewal to ISO/IEC 25000 series in software quality standards. ISO/IEC 9126-1 [6] was renewed to ISO/IEC 25010 [7] and the definition of usability was renewed. Unlike ISO 9241-210, the terminology UX is not used in ISO/IEC 25010. Instead, concepts of UX are included in the definition of satisfaction of usability definition; Satisfaction consists of not only usefulness but also trust, pleasure, and comfort.

\section{Discussion}

So far, related research results and related international standards to UX are reviewed. In this section, discussions are made on what are missing in the international standards to represent the notion of UX, and a framework on UX is newly proposed based on the discussions.

\subsection{Different Kinds of Goals for UX}

For a development of systems and services, clarifying user's goals with the systems and services is very important as emphasized in the international standards described in section three. "Goal" is defined in ISO 9241-11as "an intended outcome", which can be decomposed into sub-goals and accomplishing sub-goals result in accomplishment of an original goal.

When ISO 9241-11 is extended to cover not only usability but also UX, this definition of "goal" (intended goal) needs to be wider. Firstly, in addition to the intended goal, "expected" goal which can not be explicitly decomposed into sub-goals should be added to the notion of goal. Because, when it comes to service, it is often the case that what a customer thinks of for UX is expectation rather than the intended goal in the sense that expectation is so abstract to be decomposed into sub-goals [11]. Examples of the expected goal include "Be able to capture what she sees in 'her mind's eye', "[4].

Secondly, emotional goal should also be added since it is also difficult to be decomposed into sub-goals. Examples include "Feel like a 'real' photographer" [4].

Summaries are shown in Table 2. Three kinds of goals are added to the goal of ISO 9241-11. These different kinds of goals should be mentioned in ISO 9241-11 in the future. 
Table 2. Four kinds of goals which should be covered by UX (“+” means addition to ISO 9241-11.)

\begin{tabular}{|c|c|c|}
\hline & actional & emotional \\
\hline Intended goal & ISO 9241-11 & + \\
\hline Expected goal & + & + \\
\hline
\end{tabular}

\subsection{Different Kinds of Activities for Long Time Spans of UX}

Fig.1 explained that time spans of UX are longer than that of usability, which is slightly mentioned in ISO 9241-210 [9].

When longer time spans are considered, two kinds of activities should be differentiated. First is a development activity that is based on existing usability activities and seeks for higher satisfaction than usability for UX. In this sense, this kind of activities could be called as for "Usability Experience" rather than for UX. Examples include activities conducted by Ease of Use Roundtable [18]. Their documents provide guidelines to solve basic usability issues considering wider time spans from Out of Box Experience to Maintenance and Serviceability. Another example is a Persona method which aims at high UX [4].

Second is not an extension of usability activity but an activity that various departments share some UX goal for a system or service and cooperate with each other for better UX throughout the product lifecycle. For this kind of activity, each department uses its own existing methods related to customer satisfaction and considers UX additionally.

These different kinds of activities and Fig.1 should be addressed in ISO 9241-210 in the future.

\subsection{UX Framework}

Since framework explains a notion by describing components and relationship among them, it is important to create a framework for a specific notion. Usability framework is explained in ISO 9241-11 as mentioned in section 3.1. In this section, considering discussions in section 4.1 and 4.2, UX framework is discussed and a new UX framework is proposed.

As a framework for UX in the international standard, it is preferable to satisfy the following conditions: 1) it fits together with existing standards, 2) it shows components of UX and relationship among them, 3) it encompasses notion of time spans explained in section 4.2,4) it can differentiate goals explained in section 4.1, 5) it fits together with an well known existing framework to treat expectation.

Since ACSI of section 2.6 meets these conditions, it is adopted here as a base framework for further refinement. Fig. 3 shows the result of refinement and proposes a new framework based on ISO 9241-11 and ACSI. Three major components and relationship among them are deployed similar to ISO 9241-11: goals, context of use, and measures. In the UX measure component, most components of ACSI are deployed. Since meanings of small components such as goals, perceived quality, and 
perceived value are changed from ISO 9241-11 and ACSI, they are explained in the following. First, considering section 4.1, "goals" are specified as composed of intended goals and expected goals.

Second, meaning of "perceived quality" is extended as composed of various qualities such as those mentioned in section 2.5. In ACSI, "perceived quality" was calculated as a total score of desired and undesired degrees against needs. As discussed in section 2, since quality measures of UX other than satisfaction and long term measures vary a lot, appropriate measures should be selected for a system and a service.

Third, meaning of "perceived value" is changed as relative quality against input compared with the relative quality against price in ACSI. Examples of "perceived value" include relative pleasure against stress in game, relative relief against anxiety in public machine usage, and so on. Although usability international standards do not treat a value as a measure, it should be added to consider UX.

Since ACSI has been widely applied to many services, the proposed framework can also be applied to many systems and services.

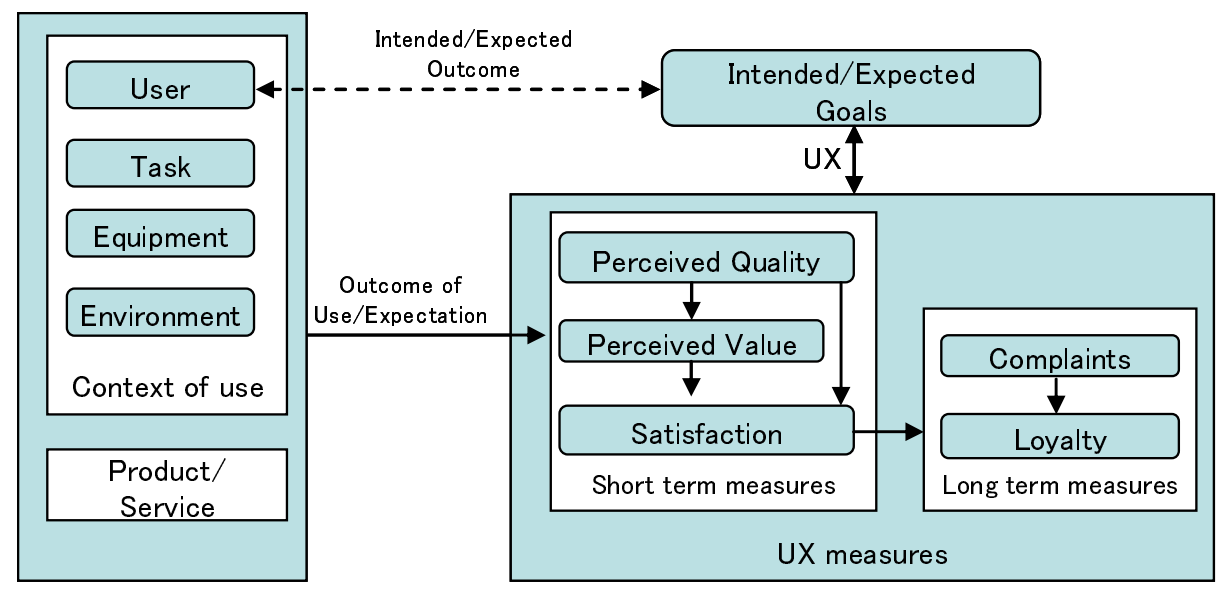

Fig. 3. Proposed UX framework based on ISO 9241-11 and ACSI

\section{Concluding Remarks}

After reviewing related research results, this paper firstly reviewed a historical transition from usability to UX by seeing transitions from ISO/IEC 9126-1 to ISO/IEC 25010 in the software quality international standard, and from ISO 13407 to ISO 9241-210 in the ergonomics international standard. Then details of the notion are discussed and a framework for UX is proposed.

Since UX is a complex notion [5], the proposed framework is expected to be applied and examined against real applications. Results of this paper are also expected to be considered in the creation of UX related international standards. 


\section{References}

1. Apple: iOS human interface guidelines, http: / / developer apple.com/library/ios/navigation/

2. Bargas-Avila, J.A., Hornbæk, K.: Old wine in new bottles or novel challenges: a critical analysis of empirical studies of user experience. In: Proc. CHI 2011, pp. 2689-2698. ACM, New York (2011)

3. Christensen, C.M.: The Innovator's Dilemma: The revolutionary book that will change the way you do business. Harvard Business School (1997)

4. Goodwin, K.: Designing for the digital age: how to create human-centered products and services. Wiley (2009)

5. Hartson, R., Pyla, P.S.: The UX Book: Process and Guidelines for Ensuring a Quality User Experience. Morgan Kaufmann (2012)

6. ISO/IEC 9126-1: Software engineering - Product quality - Part 1: Quality model. ISO/IEC (2001)

7. ISO/IEC 25010: Systems and software engineering - Systems and software Quality Requirements and Evaluation (SQuaRE) - System and software quality models. ISO/IEC (2011)

8. ISO 13407: Human-centred design processes for interactive systems. ISO (1999)

9. ISO 9241-210: Ergonomics of human-system interaction - Part 210: Human-centred design for interactive systems. ISO (2010)

10. ISO 9241-11: Ergonomic requirements for office work with visual display terminals (VDTs) - Part 11: Guidance on usability. ISO (1998)

11. Miki, H., Hosono, N., Yamamoto, S.: Transcending Human-centered Design by Service Sciences. In: Smith, M.J., Salvendy, G. (eds.) HCI International 2009, Part I. LNCS, vol. 5617, pp. 685-692. Springer, Heidelberg (2009)

12. Moser, C., Fuchsberger, V., Tscheligi, M.: A Value-based UX evaluation, http://di.ncl.ac.uk/uxtheory/files/2011/11/11_Moser.pdf (electronic version)

13. Nielsen, J.: Usability Engineering. Morgan Kaufmann (1994)

14. Norman, D.A.: Invisible Computer: Why good products can fail, the personal computer is so complex and information appliances are the solution. MIT, Cambridge (1998)

15. Obrist, M., et al.: In Search of Theoretical Foundations for UX Research and Practice. In: Proc. CHI 2012 Extended Abstracts, pp. 1979-1984. ACM, New York (2012)

16. Roto, V., et al.: User Experience White Paper, http: / /www. allaboutux. org/uxwhitepaper (electronic version)

17. Sheth, J.N., Newman, B.I., Gross, B.L.: Why we buy what we buy: a theory of consumption values. J. Business Research 22(2), 159-170 (1991)

18. Solenson, P.: Intel's Ease of Use/PC Quality Roundtables http: / /www.usabilityprofessionals.org/upa_publications / upa_voice/volumes/4/issue_1/intel_ease.htm (electronic version) 